\title{
Response of arbuscular mycorrhizal fungi on growth and chlorophyll content of three varieties of Gossypium herbaceum L.
}

\section{Arun Arya ${ }^{1}$ and Hiral Buch ${ }^{2} *$}

\author{
${ }^{1}$ Department of Botany, Faculty of Science, The Maharaja Sayajirao University of Baroda, Vadodara-390002, India \\ ${ }^{2}$ Department of Botany, Faculty of Science, The Maharaja Sayajirao University of Baroda, Vadodara-390002, India
}

Arun Arya, Hiral Buch 2013 - Response of Arbuscular Mycorrhizal Fungi on Growth and Chlorophyll Content of Three Varieties of Gossypium herbaceum L. Plant Pathology \& Quarantine 3(1), 54-57, doi 10.5943/ppq/3/1/8

Cotton (Gossypium herbaceum L.) is an important cash crop of Gujarat and Maharashtra in India. Soil microflora play a significant role in plant growth. A large number of hybrid and Bt cotton varieties are introduced in the field. Considering the fact that not much data is available on effect of AM fungi on growth performance of cotton varieties, the present study was planned to investigate the effect of arbuscular mycorrhizal fungi on growth and chlorophyll content three different varieties of cotton. A significant increase in all the varieties (Non Bt, Ajeet-11 and Vikram-5) over control in root and shoot length and their dry weight, was recorded. Changes in chlorophyll contents of $\mathrm{a}, \mathrm{b}$ and total chlorophyll were also observed. It is clear from the observation that the inoculation of cotton plants with AM fungi was helpful in enhancing the plant growth.

Key words - AM Fungi - chlorophyll - Gossypium herbaceum L.

\section{Article Information}

Received 28 April 2013

Accepted 24 May 2013

Published online 25 June 2013

*Corresponding author: Hiral Buch- hirbuch@ gmail.com

\section{Introduction}

Cotton (Gossypium herbaceum L.) "King of Fibre", belonging to the family, Malvaceae is one of the most important and widely cultivated commercial cash crops across the world. India is the second largest producer of cotton (Biology of Cotton, http:// www.dbtbiosafety.nic.in).

The arbuscular mycorrhizal fungi (AMF) are obligate biotrophs which lead to a symbiotic life, characterized by the transfer of nutrients, especially phosphorus, which has been taken up from the soil by the hyphae of fungi, and in turn they obtain carbohydrates provided by the host plants (Hampp and Schaeffer, 1995; Smith and Read, 1997). AMF are found in many soils around the world, and they form association with $80 \%$ of all terrestrial plant roots (Harley and Harley, 1987). The symbiotic association between AMF and roots provides a significant contribution to plant nutrition and growth.

AMF significantly increase the net photosynthesis by increasing the total chlorophyll and carotenoid contents ultimately increasing carbohydrate accumulation (Manoharan et al., 2008). Shrestha et al. (1995) have shown that photosynthesis and transpiration rates of mycorrhizal Satsuma mandarian trees were higher than nonmycorrhizal trees. Mycorrhizal turf, creeping bent grass had maintained significantly higher 
chlorophyll concentration than nonmycorrhizal turf during the drought period (Manoharan et al., 2008). Wright et al. (1998) also showed that mycorrhizal Trifolium repens L. exhibited a higher specific leaf area and increased rate of photosynthesis as compared with non-mycorrhizal plants. The chlorophyll content, fresh weight and leaf area were higher in mycorrhizal plants than in non-mycorrhizal plants but differences were significant only under draught stress conditions (Morte et al., 2000).

The present study was undertaken to study the effect of AMF on the changes in plant growth and chlorophyll content of three varieties of cotton.

\section{Materials and Methods}

The present study was conducted during August 2011 and December 2012 in the Dept. of Botany, The M. S. University of Baroda, Vadodara, Gujarat, India to observe the effect of AM fungi on the growth and chlorophyll content of three cotton varieties. The soil used for the study was of Botanical Garden of the M.S. University. The seeds of three varieties of cotton viz. Non Bt, Ajeet-11 and Vikram-5 were obtained from the Azad agency, Vadodara, Gujarat. The seeds were surface sterilized and sown in the plots filled with the mixture of garden soil and sand mixture at the ratio of $2: 1(\mathrm{v} / \mathrm{v})$. Seeds were sown with AM fungi (applied as layering on soil surface). One of the plot were kept without the applying the layer of AM fungi as control. AM fungi used for the inoculation was Glomus fasciculatum. The experimental design was completely randomized block design.

The plants were irrigated with tap water as and when required. The leaves were collected from each treatment for sampling on 15th, 30th, and 45th day after sowing and estimation of chlorophyll content was done following the method of Sadasivan and Manickam (1996). Plant shoot and root length, dry weight of shoot and root, total number of nodules per plant, dry weight of nodules per plant and root colonization of AM was calculated at 45 th day. Root colonization of AM fungi was estimated by Trypan blue technique as suggested by Phillips \& Hayman (1970). All the measurements were carried out in triplicates and the results are expressed as the average of the three replicates.

\section{Results and Discussion}

The plants inoculated with AM fungi significantly increased the shoot length and root length, dry weight of shoot and root when compare to control. The plants inoculated with AM fungi showed maximum values in all the tested parameter than control plants (Table 1). Results of the experiments confirm various reports on enhanced plant growth due to AM inoculation to medicinal plants (Earanna, 2001; Bobby \& Bagyaraj, 2003; Nisha \& Rajeshkumar, 2010) and forest trees species (Vasanthakrishna et al., 1995; Rajan et al., 2000).Similar observations were made by Patterson et al. (1990) and on Vigna unguiculata (L) Walp var. Pusa 151 by Arumugam et al, (2010).

The plants inoculated with AM fungi showed positive AM fungi colonization in roots. uninoculated control plants do not have colonization. The high frequency of $88 \%$ of infection was observed in roots of AM fungi inoculated plants of Ajeet-11 variety and 90\% in case of Vikram-5 whereas non Bt variety showed $75 \%$ of root infection (Table 1).

Table 1 Effect of AM Fungi on growth parameters of two varieties of G. herbaceum

\begin{tabular}{lllllll}
\hline & Non Bt & $\begin{array}{l}\text { Non Bt } \\
\text { AM }\end{array}$ & $\begin{array}{l}\text { Control } \\
\text { Ajeet-11 }\end{array}$ & $\begin{array}{l}\text { Ajeet-11 } \\
\text { AM }\end{array}$ & $\begin{array}{l}\text { Control } \\
\text { Vikram-5 }\end{array}$ & $\begin{array}{l}\text { Vikram-5 } \\
+ \text { AM }\end{array}$ \\
\hline Shoot Length $(\mathrm{cm})$ & $38.66 \pm 0.5$ & $54.62 \pm 1.0$ & $42.0 \pm 2.6$ & $50.3 \pm 2.1$ & $44.3 \pm 1.8$ & $54.7 \pm 1.7$ \\
Root Length $(\mathrm{cm})$ & $13.0 \pm 0.5$ & $28.0 \pm 0.8$ & $17.0 \pm 1$ & $20.0 \pm 0.5$ & $18.0 \pm 1$ & $30.3 \pm 2$ \\
Dry weight Shoot $(\mathrm{g})$ & $3.40 \pm 0.7$ & $20.8 \pm 0.5$ & $4.3 \pm 0.1$ & $9.05 \pm 0.7$ & $11.3 \pm 0.5$ & $20.8 \pm 0.5$ \\
Dry weight Root $(\mathrm{g})$ & $0.404 \pm 0.5$ & $1.66 \pm 0.5$ & $0.7 \pm 0.2$ & $1.10 \pm 0.1$ & $1.0 \pm 0.2$ & $1.70 \pm 0.7$ \\
Mycorrhizal & - & $75 \pm 0.2$ & - & $88 \pm 0.3$ & - & $90 \pm 0.5$ \\
Colonization $(\%)$ & & & & & & \\
\hline
\end{tabular}




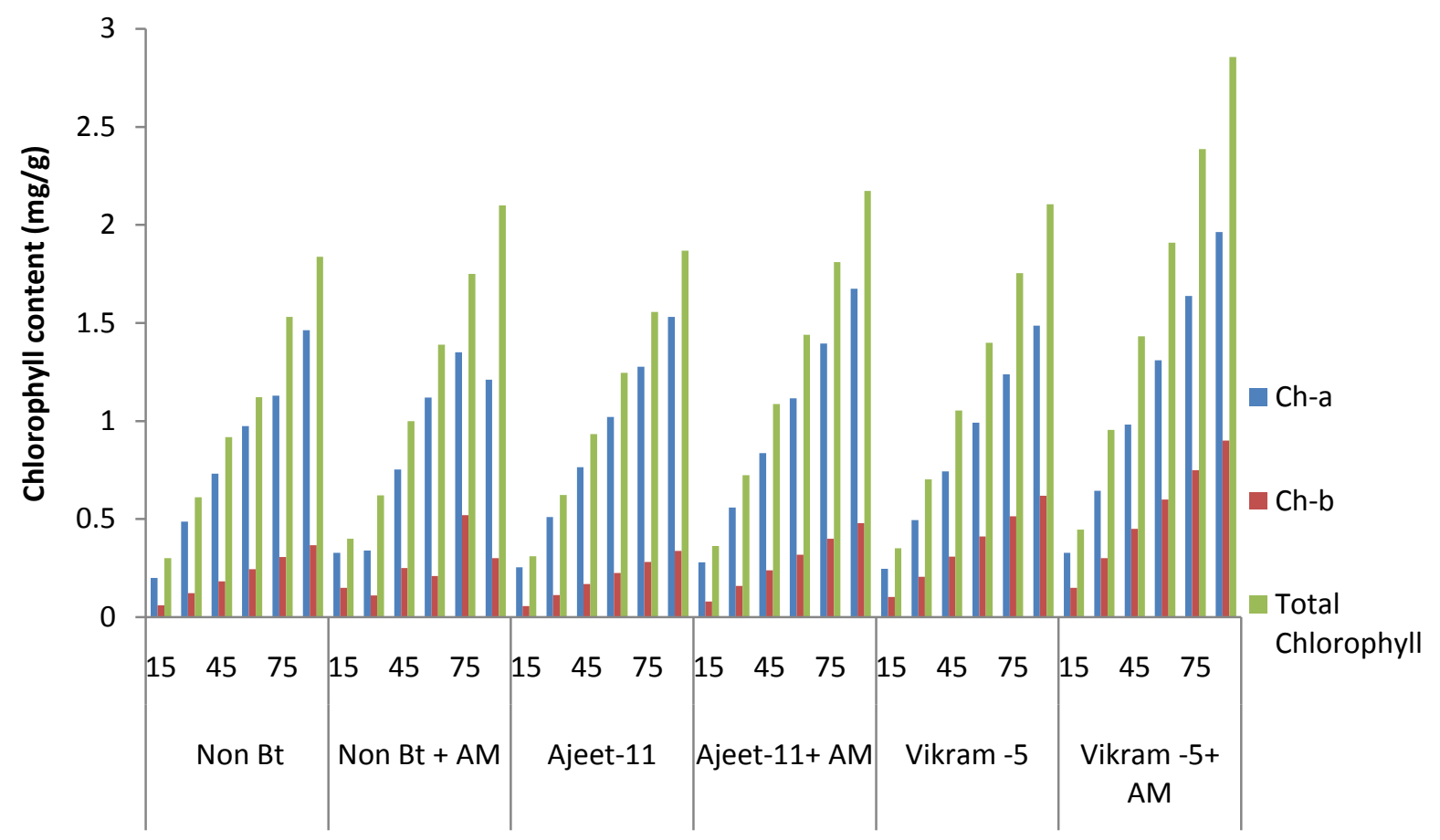

Number of Days and G. herbaceum varieties

Fig. 1 - Histograph showing chlorophyll content of three varieties of G. herbaceum after every 15 days

Plants inoculated with AM fungi brought about significant changes in chlorophyll a, b and total chlorophyll content. The maximum total chlorophyll content was noticed at 90 days old sampling leaves as compared to the uninoculated plants (Fig.1).

A considerable increase in chlorophyll content of AM fungi inoculated tissue of cowpea is in agreement with results reported elsewhere (Hayman 1983). This increase may be due to an increase in stomatal conductance, photosynthesis, transpiration and enhanced plant growth (Hayman, 1983; Sampath \& Ganesh, 2003; Rajasekaran et al. 2006) or due to the presence of large and more numerous bundle sheath chloroplasts in the inoculated leaves (Krishna \& Bagyaraj, 1984).

\section{Conclusions}

It is evident from the experiments conducted on three varieties of cotton that there was significant increase in shoot and root length of both non Bt and 2 varieties of $G$. herbaceum plants. Dry wt. of AM inoculated plants of cotton both Bt and non Bt increased. This increase may be directly correlated with the increase in content of chlorophyll-a and total chlorophyll. This increase was more pronounced between 45 and 90 days. The increase in plant growth and yield of crops like cotton gives a clue to use AM fungi as a tool to enhance plant biomass and yield of various other crops. Inoculum can be raised and crop yield can be increased by changing the soil mycoflora.

\section{References}

Arumugam R, Rajasekaran S, Nagarajan SM 2010 - Response of Arbuscular mycorrhizal fungi and Rhizobium inoculation on growth and chlorophyll content of Vigna unguiculata (L) Walp Var. Pusa 151, Journal of Applied Sciences \& Environmental Management, 14 (4) 113-115. 
Bobby V U, Bagyaraj D J 2003 - Biological control of root rots of Coleus forskohlii Briq. using microbial inoculants, World Journal of Microbiology and Biotechnology. 19 175-185.

Earanna N 2001 - VA mycorrhizal association in medicinal plants of Southeastern dry zone of Karnataka and response of Phyllanthus amarus and Withania somnifera to inoculation with VAM fungi and plant growth promoting rhizomicroorganisms. Ph.D thesis. Submitted to University of Agricultural Sciences, Bangalore.

Harley J L, Harley E L 1987 - A check-list of mycorrhiza in the British flora, New Phytologist , 105 1-102.

Hayman D S 1983 - The physiology of vesicular arbuscular endomycorrhizal symbiosis, Canadian Journal of Botany, 61, 944-963.

http://www.dbtbiosafety.nic.in/guidelines/cotto n.pdf

Krishna K R, Bagyaraj D J 1984 - Growth and nutrient uptake of peanut inoculated with mycorrhizal fungus Glomus fasciculatum compared with uninoculated ones, Plant and Soil, 17, 405-408.

Manoharan P T, Pandi M, Shanmugaiah V, Gomathinayagam S, Balasubramanian N 2008 - Effect of vesicular arbuscular mycorrhizal fungus on the physiological and biochemical changes of five different tree seedlings grown under nursery conditions, African Journal of Biotechology, 7, 3431-3436.

Morte A, Lovisola C, Schubert A, 2000 Effect of drought strtess on growth and water relations of the mycorrhizal association Helianthemum almerienseTerfezia clavery, Mycorrhiza, 10(3) 115-119.

Nisha M C, Rajeshkumar S 2010 - Effect of arbuscular mycorrhizal fungi on growth and nutrition of Wedilia chinensis (Osbeck) Merril., Indian Journal and Technology, 3(6) 676-678.

Patterson N A, Cheit I, Kapulink Y 1990 Effect of Mycorrhizal inoculation on nodule initiation activity and contribution to legume productivity symbiosis, Annals of Biology, 8 9-20.

Phillips J M, Hayman D S 1970 - Improved procedures for clearing roots and staining parasitic and vesicular arbuscular mycorrhizal fungus for rapid assessment of infection, Transactions of the British Mycological Society, 55 158-161.

Rajasekaran S, Nagarajan S M, Arumugam K, Sravanamuthu R, Balamurugan S 2006 - Effect of dual inoculation (AM fungi and Rhizobium) on Chlorophyll content of Arachis hypogaea L. CV. TMV-2., Plant Archives, 6(2) 671-672.

Reddy S K, Bagyaraj D J 2000 - Screening of arbuscular fungi for their symbiotic efficiency with Tectona grandis., Forest Ecology Management, 126 9195.

Sadasivam S, Manickam A 1996 Biochemical Methods. $2^{\text {nd }}$ edn, New Age International Private Limited and Tamilnadu Agricultural University, Coimbtore.

Sampath kumar G, Ganesh kumar A 2003 Effect of AM fungi and Rhizobium on growth and nutrition of Vigna mungo L. and Vingna unguiculata L., Mycorrhiza News, 14(4) 15-18.

Shrestha Y H , Ishll T, Kadoya K 1995 Effects of VAM fungi on the growth, photosysnthesis, transpiration and the distribution of photosynthates of bearing satsuma mandarin trees., Journal of Japanese Society for Horticultural Science, 64, 517-525.

Smith S M, Read D. 1997 - Mycorrhizal Symbiosis $2^{\text {nd }}$ ed. Academic Press, London

Vasanthakrishna M., Bagyaraj D J, Nirmalnath J P 1995 - Selection of efficient VA mycorrhizal fungi for Casuarina equisetifolia - Second screening, New Forests, 9, 157-162.

Wright D P, Scholes J D, Read D J 1998 Effects of VAM colonization on photosynthesis and biomass production of Trifolium repens L., Plant Cell Environment, 21, 209-216. 